\title{
Investigations into Optimization Models of Crude Oil Distillation Column in the Context of Feed Stock and Market Value
}

\author{
Lekan T. Popoola ${ }^{1}$, Jamiu A. Adeniran ${ }^{2}$, Solomon O. Akinola ${ }^{3}$ \\ ${ }^{1}$ Department of Petroleum and Chemical Engineering, Afe Babalola University, Ado-Ekiti, Nigeria \\ ${ }^{2}$ Department of Chemical Engineering, Ladoke Akintola University of Technology, Ogbomoso, Nigeria \\ ${ }^{3}$ Department of Computer Engineering, Afe Babalola University, Ado-Ekiti, Nigeria \\ Email: popoolalekantaofeek@yahoo.com
}

Received July 14, 2012; revised August 25, 2012; accepted September 3, 2012

\begin{abstract}
This paper proposes optimization models of crude oil distillation column for both limited and unlimited feed stock and market value of known products prices. The feed to the crude distillation column was assumed to be crude oil containing naphtha gas, kerosene, petrol and diesel as the light-light key, light key, heavy key and heavy-heavy key respectively. The models determined maximum concentrations of heavy key in the distillate $\left(\overline{H K}_{D}\right)_{0}$ and light key in the bottom $\left(\overline{L K}_{B}\right)_{0}$ for limited feed stock and market condition. Both were impurities in their respective positions of the column. The limiting constraints were sales specification concentration of light key in the distillate $\left[\left(L K_{D}\right) \geq\left(L K_{D}\right)_{s s}\right]$, heavy key in the bottom $\left[\left(H K_{B}\right) \geq\left(H K_{B}\right)_{s s}\right]$ and an operating loading constraint of flooding above the feed tray. For unlimited feed stock and market condition, the optimization models determined the optimum separation $\left[\left(\overline{H K}_{D}\right)_{0}\right.$ and $\left.\left(\overline{L K}_{B}\right)_{o}\right]$ and feed flow rate $\left(F_{o}\right)$ that would give maximum profit with minimum purity sales specification constraints of light key in the distillate and heavy key in the bottom as stated above. The feed loading was limited by the reboiler capacity. However, there is need to simulate the optimization models for an existing crude oil distillation column of a refinery in order to validate the models.
\end{abstract}

Keywords: Feed Stock; Crude Oil Distillation Column; Constraints; Market Condition; Reboiler; Crude Composition; Optimization

\section{Introduction}

While the use of distillation dates back in recorded history to about 50 B.C., the first truly industrial exploitation of this separation process did not occur until the 12th century when it was used in the production of alcoholic beverages [1]. Crude oil distillation is the separation of the hydrocarbons in crude oil into fractions based on their boiling points which lie within a specified range [2]. The separation is done in a large tower (Crude Oil Distillation Column) that is operated at atmospheric pressure. The tower contains a number of trays where hydrocarbon gases and liquids interact. The liquids flow down the tower and the gases up [3]. The fractions that rise highest in the column before condensing are called light fractions, and those that condense on the lowest trays are called heavy fractions [4]. The portion of the column above the feed iscalled the rectifying section and below the feed, the stripping section.Globally, more than 80 million barrels of crude oil are refined daily. In the US, 146 refineries operate, employing over 65,000 people and producing a total value that exceeds $\$ 151$ billion [5]. Figure $\mathbf{1}$ gives a schematic representation of the process overview of a crude oil distillation column.

Crude Distillation Units (CDUs) are key process plants in a petroleum refinery as changes in these units have a great impact on product yield and quality. It is recommended to operate these units at optimal conditions from technical and economical points of view. Mathematical modelling has become very common to develop these optimization studies [6]. Many conventional ways of optimizing crude oil distillation column such as total 


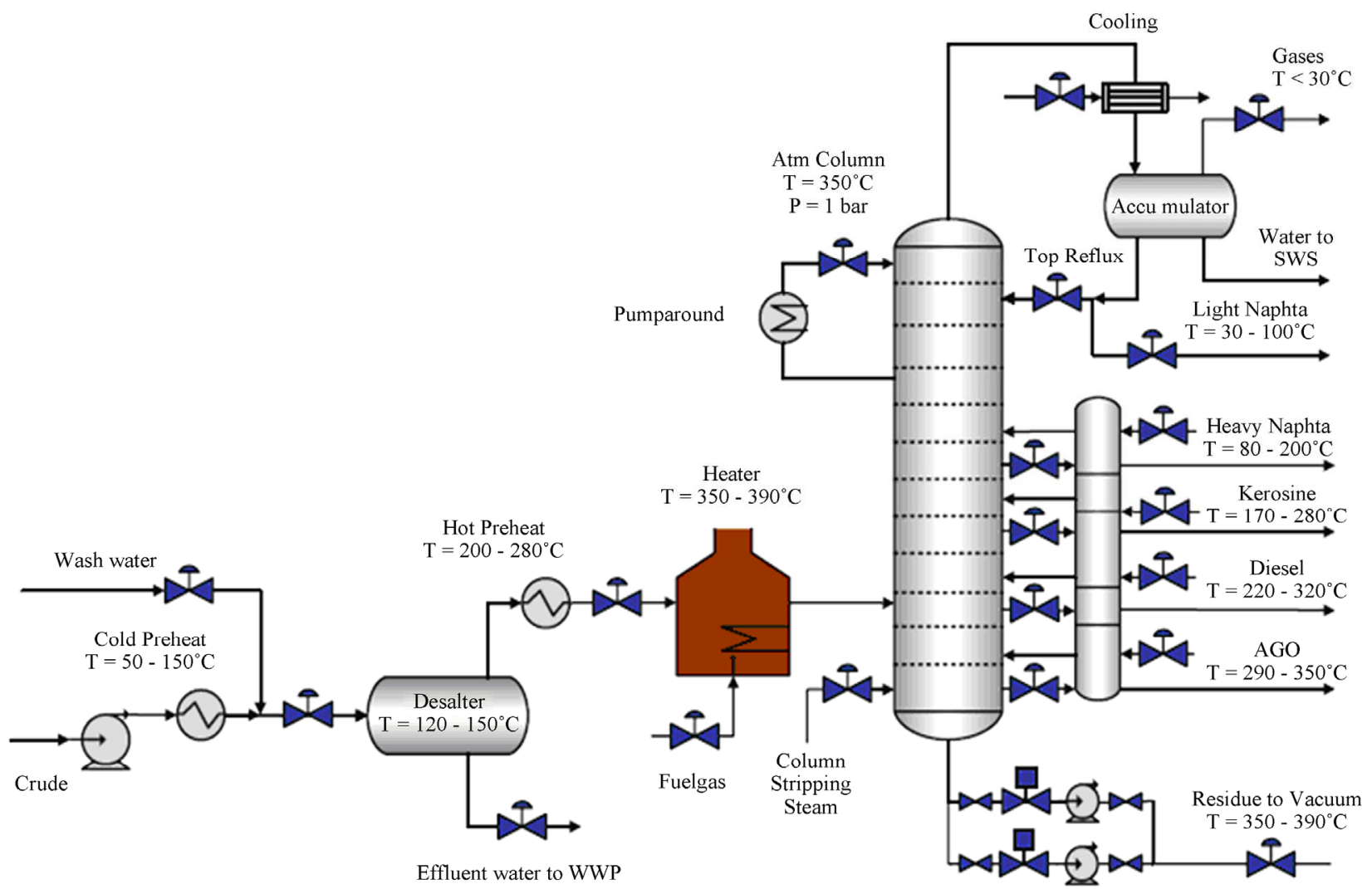

Figure 1. Process overview of crude oil distillation column.

energy requirement, heat integration, enhanced crude blending, crude oil energy consumption, operating conditions, products specification and many more had been discovered by previous researchers. Yu et al. [7] proposed an on-line soft-sensor for the quality control and energy optimization of crude distillation column. A two-stage soft sensor was developed for the estimation of internal liquid and vapour loads, and product quality specifications of side streams. The measurements of the soft-sensor were used to derive the constraints of the energy optimization system as well as feedback to the quality control system. Gadalla et al. [8] developed optimization framework which included shortcut models for the simulation of the existing distillation column and a retrofit shortcut model for the heat exchanger network. The process was optimized by changing key operating parameters while simultaneously accounting for hydraulic limitations and design including the performance of the existing heat exchanger network. A reduction in energy consumption and operating costs of over $25 \%$ was achieved. In 2003, Okeke et al. [9] proposed the design and optimization of a crude distillation unitat the Nigeria Port Harcourt refinery in the context of total energy requirement. The modelling procedure used was a stagewise approach to determine opportunity for optimization using sequential quadratic programming (SQP). They concluded that the programming technique was ideal for solution of the algorithm achieving quick convergence and $8 \%$ gasoline yield increment. Domijan et al. [10] made improvement on research done by Yu et al. [7] and Okeke et al. [9] by considering off-line energy optimization model for crude distillation unit. The CDU model was a non-stage-by-stage, steady-state model and corrected by real process values. The model calculated the yields and properties of the products based on feed information and product specifications. The optimal solution obtained showed that the energy consumption could be decreased 3.2\% over the normal operating condition. Fazlali et al. [11] also considered an energy saving option in refinery industry but used operating conditions to optimize the distillation columns. The atmospheric distillation unit of Iran-Arak-Shazand petroleum refinery was subjected to optimization efforts using a simulator with theaim to earning more overhead products. Results demonstrated that changes in the real operating conditions increased the overhead products with desirable quality. Kozarev et al. [12] investigated the optimization of crude distillation units using the knowledge of computer aided steady state control to optimize the mode of operation of a crude oil column with respect to the product prices, energy consumption and standard requirements of products compositions. A simple non-iterative 
mathematical model of a crude oil distillation tower together with an appropriate technique was presented. The results revealed that a good separation at considerably low quantity of reflux could be realized. The use of the short-cut model made the optimization procedure to be very fast. Benyoucef [13] worked on oil refining planning under price and demand uncertainties using Algeria as a case study. His paper aimed at analysing the Algerian refining industry development in the presence of uncertainties for both domestic products demand and the international markets. Considering multiple uncertainties on demand and oil price, the model provided the production levels, the rate units running and the foreign trade of products by the year 2030. Hassan et al. [14] improved on the work done by Benyoucef [13] by using linear programming modelling to improve oil refinery productivity but through enhanced crude blending. The objective of their study was to develop a mathematical programming model for solving a blending problem in a major refinery Alexandria, Egypt with the objective of maximizing naphtha productivity. Their study showed that the developed linear programming model for the blending problem yielded better overall naphtha productivity for the oil refinery studied as compared to the results obtained from the commercial software.

\section{Proposed Optimization Models}

The optimization models proposed are applicable for known product prices of crude oil distillation column in order to obtain the specified separation for the least operating cost under the conditions of both limited and unlimited market and feed stock. It is impossible to maximize the profit without knowing the prices of terminal products of the distillation column and taking into account all other aspects of the overall plant in which the column is a part. The feed to the crude distillation column is assumed to be crude oil containing naphtha gas, kerosene, petrol and diesel as the light-light key, light key, heavy key and heavy-heavy key respectively. The limited market and feed stock optimization models are presented for the conditions in which the top products are more valuable than the bottom products and vice versa.

\subsection{Product Prices Known with Limited Market and Feed Stock}

Condition 1: Top products are more valuable than the bottom products

Since it is assumed that the top products have the highest unit prices, they must be produced at minimum specified purity such that the heavy key component in the top product $\left(\mathrm{HK}_{\mathrm{D}}\right)$ is the impurity present in the distillate and hence, the control component. The maximum concentration of the heavy key in the distillate is calculated thus (see below):

where

$\left(\overline{H K}_{D}\right)_{0}=$ Optimum concentration of heavy key in the distillate, $\mathrm{mol} / \mathrm{m}^{3}$,

$L K_{F}=$ Concentration of the light key in the feed, $\mathrm{mol} / \mathrm{m}^{3}$,

$\overline{L K}_{B}=$ Concentration of the light key in the bottom, $\mathrm{mol} / \mathrm{m}^{3}$,

$L L K_{F}=$ Concentration of the light-light key in the feed, $\mathrm{mol} / \mathrm{m}^{3}$,

$\left(L K_{D}\right)_{s s}=$ Sales specification concentration of light key in the distillate, $\mathrm{mol} / \mathrm{m}^{3}$.

When the change in operating cost equals the change in product worth,

$$
(P D-P B)\left[\frac{\partial(D)}{\partial\left(\overline{L K}_{B}\right)}\right]=C L_{i}\left[\frac{\partial\left(L_{i}\right)}{\partial\left(\overline{L K}_{B}\right)}\right]
$$

where

$P D=$ Price of the distillate, $\mathrm{N} / \mathrm{sec}$,

$P B=$ Price of the bottom, $/ \mathrm{sec}$,

$D=$ Distillate concentration, $\mathrm{mol} / \mathrm{m}^{3}$,

$C L_{i}=$ is the unit cost of operation per unit of internal reflux, $\mathrm{N}\left(\mathrm{s} / \mathrm{m}^{3}\right)$,

$L_{i}=$ internal reflux, $\mathrm{m}^{3} / \mathrm{s}$,

$\overline{L K}_{B}=$ Concentration of the light key in the bottom, $\mathrm{mol} / \mathrm{m}^{3}$.

The simultaneous solution of Equations (1) and (2) gives the the optimum values of $H K_{D}$ and $\overline{L K}_{B}$. The light key in the distillate $\left(L K_{D}\right)$ is the purity component in the top product and thus, its purity concentration must not be less than that of the sales specification. Hence, the limiting constraint equation for Equations (1) and (2) above is:

$$
\left(L K_{D}\right) \geq\left(L K_{D}\right)_{s s}
$$

where $\left(L K_{D}\right)_{s s}$ is the sales specification concentration of the light key in the distillate, $\mathrm{mol} / \mathrm{m}^{3}$.

Condition 2: Bottom products are more valuable than the top products

When the bottom products are assumed to be more valuable than the top products, light key in the bottom $\left(L K_{B}\right)$ becomes the impurity and its maximum concentration in the bottom products should be determined as the controlling component. Thus, we have

$$
\left(\overline{H K}_{D}\right)_{0}=\frac{\left(L K_{F}\right)+\left(\overline{L K}_{B}\right)\left[\left(L L K_{F}\right)-1\right]-\left(L K_{D}\right)_{s s}\left[\left(L L K_{F}\right)+\left(L K_{F}\right)-\left(\overline{L K}_{B}\right)\right.}{\left(L K_{F}\right)-\left(\overline{L K}_{B}\right)}
$$




$$
\left(\overline{L K}_{B}\right)_{\max }=\frac{\left[1-\left(\overline{H K}_{D}\right)_{o}\right]\left[\left(L L K_{F}\right)+\left(L K_{F}\right)+\left(H K_{F}\right)+\left(\overline{H K}_{B}\right)_{S s}\right]-\left[\left(L L K_{F}\right)+\left(L K_{F}\right)\right]\left[1-\left(\overline{H K}_{B}\right)_{s s}\right]}{\left(L K_{F}\right)-\left(\overline{H K}_{D}\right)_{o}}
$$

where

$\left(\overline{H K}_{D}\right)_{o}=$ Optimum concentration of heavy key in the distillate, $\mathrm{mol} / \mathrm{m}^{3}$,

$\left(\overline{H K}_{B}\right)_{s s}=$ Sales specification concentrationof heavy key in the bottom, $\mathrm{mol} / \mathrm{m}^{3}$,

$\left(H K_{F}\right)=$ Concentration of heavy key in the feed, $\mathrm{mol} / \mathrm{m}^{3}$,

$\left(\overline{L K}_{B}\right)_{\max }=$ Maximum concentration of the light key in the bottom, $\mathrm{mol} / \mathrm{m}^{3}$.

Other variables are as stated for Equations (1) and (2) above.

The heavy key in the bottom $\left(\overline{H K}_{B}\right)$ is the purity component in the bottom product whose concentration must not be less than that of the sales specification. Hence,

$$
\left(\overline{H K}_{B}\right) \geq\left(\overline{H K}_{B}\right)_{s s}
$$

The column is assumed to approach an operating constraint of flooding above the feed tray (because of excessive entrainment of liquid in the vapour) as $\left(\overline{H K}_{D}\right)$ determined from Equations (1) and (2) above is lowered. The loading equation for this constraint is given as:

$$
a_{1}+a_{3}(\bar{P})+F\left[\left(a_{2}-1\right) \frac{L_{i}}{F}+\frac{B}{F}-1\right]=0
$$

where

$a_{1}, a_{2}$ and $a_{3}=$ Coefficients of experimental loading equation,

$\bar{P}=$ Column pressure, $\mathrm{Pa}$,

$F=$ Feed flow rate, $\mathrm{m}^{3} / \mathrm{s}$,

$L=L_{i}=$ Liquid flow rate in column at the point at which flooding occurs, $\mathrm{m}^{3} / \mathrm{s}$,

$L_{i} / F$ and $B / F$ are obtained from the operating control equations for reflux and bottom product flow rate.

$B=$ Bottom flow rate, $\mathrm{m}^{3} / \mathrm{s}$.

As $\left(\overline{H K}_{D}\right)_{0}$ is reduced from optimum, $L_{i} / F$ and $B / F$ change. The value of $\left(\overline{H K}_{D}\right)_{o}$ will be obtained at a point where Equation 6 is equal to zero. That value of $\left(\overline{H K}_{D}\right)_{O}$ is used in Equation 4 to obtain $\left(\overline{L K}_{B}\right)_{\max }$. The flow chart algorithm for limited market and feed stock is shown in Figure 2.

\subsection{Product Prices Known with Unlimited Market and Feed Stock}

For an unlimited market, the feed flow rate and separa- tion resulting in maximum profit rate for the existing products must be determined. Operation for a column under this condition will always be against an operating constraint because of the unlimited market and feedstock. The overall optimization problem involves determining the optimum separation [i.e. $\left(\overline{H K}_{D}\right)_{0}$ and $\left.\left(\overline{L K}_{B}\right)_{0}\right]$, feed flow rate (i.e. $\left.F_{o}\right)$ and column pressure $\left[(\bar{P})_{o}\right]$ that will give maximum profit. The optimum concentrations of the separation, $\left(\overline{H K}_{D}\right)_{0}$ and $\left(\overline{L K}_{B}\right)_{0}$, are calculated using Equations (1) and (4) above but with the following minimum purity constraints:

$$
\begin{aligned}
& \overline{L K}_{D}=\left(\overline{L K}_{D}\right)_{s s}, \overline{H K}_{B}=\left(\overline{H K}_{B}\right)_{s s} \\
& \left(\overline{L K_{B}}\right)_{o}=\left(\overline{L K}_{B}\right)_{\max },\left(\overline{H K}_{D}\right)_{o}=\left(\overline{H K}_{D}\right)_{\max }
\end{aligned}
$$

The maximum feed flow rate is calculated by using:

$$
\begin{aligned}
F_{\max }= & a_{1}+a_{2}\left[d_{1}+d_{2}(\bar{P})-T_{c}\right] \\
& +a_{3}\left[d_{1}+d_{2}(\bar{P})-T_{c}\right]^{2}+B-L
\end{aligned}
$$

where

$a_{1}, a_{2}$ and $a_{3}=$ coefficients for condenser-loading equation that are determined by column tests

$d_{1}$ and $d_{2}=$ coefficients determined off-line from correlation of data obtained from flash calculations at the average composition of the existing overhead vapour.

$P=$ Column pressure, $\mathrm{Pa}$,

$T_{c}=$ Temperature of the coolant to overhead vapour condenser, ${ }^{\circ} \mathrm{C}$,

$B=$ Bottom product flow rates from the output of operating control equation, $\mathrm{m}^{3} / \mathrm{s}$,

$L=$ Reflux flow rates from the outputs of operating control equation, $\mathrm{m}^{3} / \mathrm{s}$,

$F_{\max }=$ Maximum feed flow rate required to load the condenser for optimum separation, $\mathrm{m}^{3} / \mathrm{s}$.

For Equation 9 above, the temperature of the overhead vapour $\left(T_{o}\right)$ is a function of column pressure only while other independent inputs are negligible.

Assuming the feed loading is limited by the reboiler capacity, the column must then be operated at minimum value in order to gain maximum reboiler capacity. Having known the optimum separation and column pressure, the the feed rate can now be increased up to the maximum capacity of the reboiler which gives the most profitable operation. The feed flow controller set point that gives the maximum reboiler heat input rate is calculated thus: 


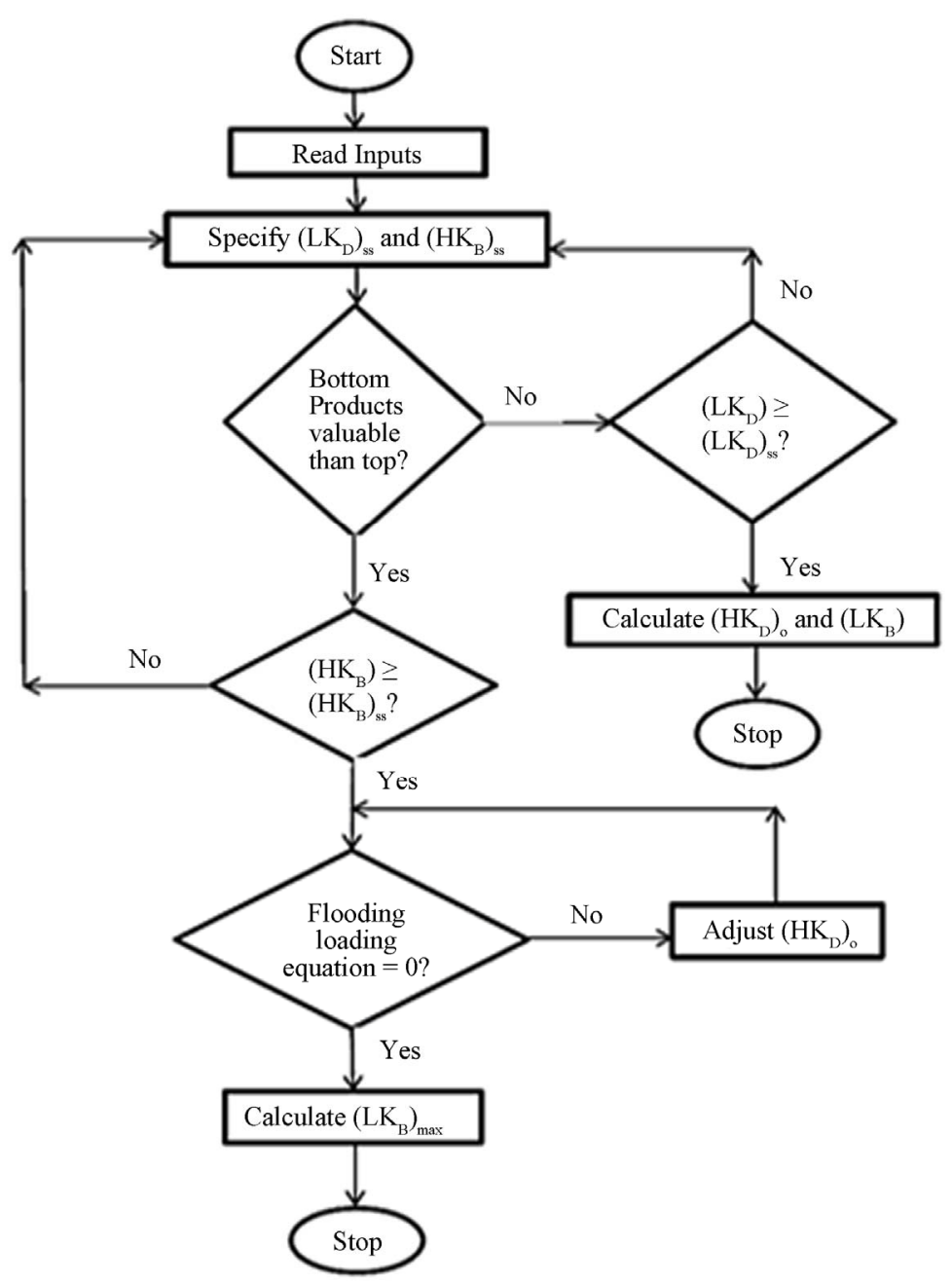

Figure 2. Flow chart optimization algorithm of crude oil distillation column for limited market and feed stock.

$$
F=\frac{\left(V_{B}\right)_{\max }}{\left(\frac{L_{i}}{F}\right)+1+\left(K_{F}\right)\left(T_{v}-T_{f}\right)-\left(\frac{B}{F}\right)}
$$

where

$F=$ Feed flow controller set point, $\mathrm{m}^{3} / \mathrm{s}$,

$\left(V_{B}\right)_{\max }=$ maximum reboiler heat input rate, $\mathrm{J} / \mathrm{s}$,

$K_{F} \stackrel{\max }{=}$ a constant equal to the specific heat of the feed divided by the heat of vaporization,

$T_{v}=$ Temperature of vapour above the feed tray, ${ }^{\circ} \mathrm{C}$,

$T_{f}=$ Temperature of the feed at column entry, ${ }^{\circ} \mathrm{C}$,

$\frac{L_{i}}{F}$ and $\frac{B}{F}$ are obtained from the operating control equations used to achieve a suboptimum operation (Figure 3).

\section{Discussion}

The existences of the feed stock and market situation which may be limited or unlimited are among major fac- tors in the determination of process optimization of crude oil distillation column. The proposed modelling equations are applicable for the process optimization of crude oil distillation column with products purity specification. Hence, the products prices and their purity specifications from customer need be known for this goal to be achieved. For known products prices of crude distillation column with limited market and feed stock, the simultaneous solution of Equations (1) and (2) gives the optimum values of the heavy key in the distillate (petrol) and light key in the bottom(kerosene). Assuming the top products are more valuable than the bottom, then the light key in the distillate (kerosene) is the purity component in the top product and thus, its purity concentration must not be less than that of the sales specification. Equation 3 is then the limiting constraints for the simultaneous solution of Equations (1) and (2). When the bottom products are assumed to be more valuable than the top products under the same condition of limited market and feed stock, the light key (kerosene) becomes the impurity in the bottom 


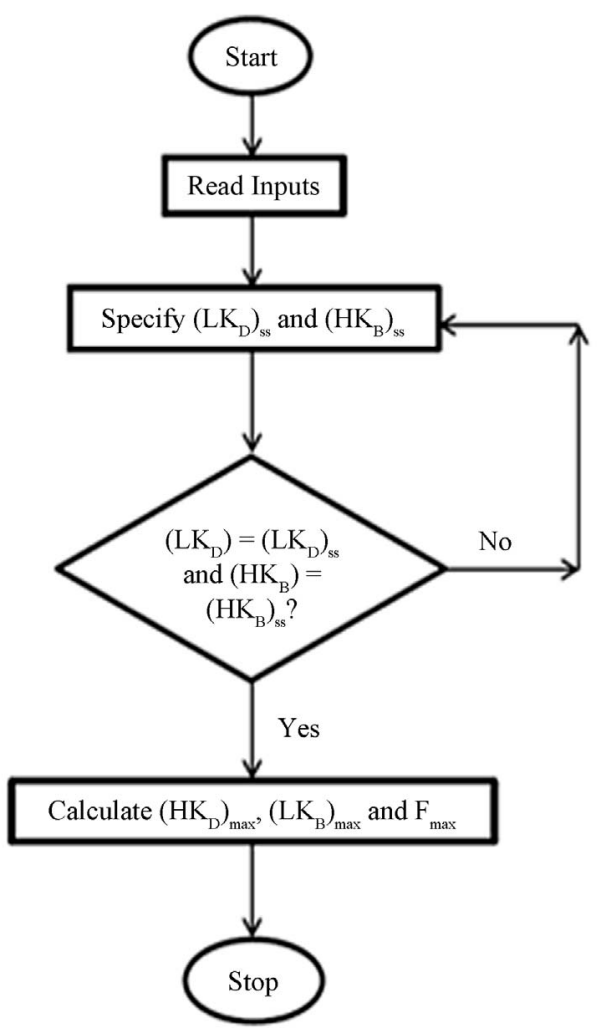

Figure 3. Flow chart optimization algorithm of crude oil distillation column for unlimited market and feed stock.

and thus, its maximum concentration is calculated by using Equation (4). However, the heavy key (petrol) in the bottom becomes its limiting constraint whose concentration must not be less than that of the sales specification (Equation (5)). To get the value of $\left(\overline{H K}_{D}\right)$ to be used in Equation (4), the column is assumed to approach an operating constraint of flooding above the feed tray. The loading equation for this constraint is stated as Equation (6). As the value of $\left(\overline{H K}_{D}\right)_{0}$ gotten from Equation (1) is reduced from optimum, the values of $\mathrm{L}_{\mathrm{i}} / \mathrm{F}$ and $\mathrm{B} / \mathrm{F}$ change. Thus, the value of $\left(\overline{H K}_{D}\right)_{o}$ that satisfies Equation (6) is obtained to solve for $\left(\overline{L K}_{B}\right)_{\max }$ in Equation (4) while other variables are stated. When unlimited market and feed stock exist with known product prices, the optimum separation [i.e. $\left(\overline{H K}_{D}\right)_{o}$ and $\left.\left(\overline{L K}_{B}\right)_{o}\right]$ is determined using Equations (1) and (4) but with the limiting purity constraints stated in Equations (7) and (8). The maximum feed flow rate that gives maximum profit rate is determined using Equation (9) in which the temperature of the overhead vapour $\left(T_{o}\right)$ is a function of the column pressure. If the feed loading is assumed to be limited by the reboiler capacity instead of the column pressure, the feed flow controller set point that gives the maximum reboiler heat input rate is evaluated using
Equation (10). The proposed optimization models can be used to simulate an existing crude oil distillation column of a refinery.

\section{Conclusion and Recommendation}

The optimization of crude oil distillation column in the context of feed stock and market condition can be achieved using the stated models. The products prices from the crude oil distillation column must be known and the consumers' products specification were put into consideration using the products limiting purity constraints. Also, the effect of operating cost on the products worth was considered by assuming that the change in operating cost equals the change in product worth. Nevertheless, the proposed optimization modelling equations are applicable for both the conditions of limited and unlimited feed stock and market situations for known product prices. The situation in which either the top products or bottom products being valuable than each other for the condition of limited feed stock and market condition had been examined. However, it is recommended that the point of introducing the feed into the column be known to validate the assumption of flooding above the feed tray. Finally, the proposed models should be tested on an existing crude oil distillation column of a refinery for future research in order to validate the applicability.

\section{REFERENCES}

[1] J. G. Kunesh, T. P. Ognisty, M. Sagata and G. X. Chen, AIChE Spring National Meeting, Atlanta, 1994.

[2] K. H. Bawazeer, "Prediction of Crude Oil Product Quality Parameters Using Neural Networks," M.S. Thesis, Florida Atlantic University, Boca Raton, 1996.

[3] W. Heather, "Refining Crude Oil," The New Zealand Refining Company Ltd., Whangarei, 2003.

[4] Z. E. H. Tonnang, "Distillation Column Control Using Artificial Neural Networks," M.Sc. Thesis, University of Ibadan, Ibadan, 2003.

[5] B. Liptak, "Distillation Control and Optimization," 2009. www.controlglobal.com

[6] D. C. López, C. A. Mahecha, L. J. Hoyos, L. Acevedo and J. F. Villamizar, "Optimization Model of a System of Crude Oil Distillation Units with Heat Integration and Metamodeling," CT \& F-Ciencia, Tecnología y Futuro, Vol. 3, No. 5, 2009, pp. 159-173.

[7] J. J. Yu, C. H. Zhou, S. Tan and C. C. Hang, “An OnLine Soft-Sensor for Control and Optimization of Crude Distillation Column," Research Institute of Industrial Process Control, Hangzhou, 1997.

[8] M. Gadalla, M. Jobson and M. Smith, "Optimisation of Existing Heat-Integrated Refinery Distillation Systems," Ph.D. Thesis, University of Manchester Institute of Science and Technology (UMIST), Manchester, 2002.

[9] E. O. Okeke and A. A. Osakwe-Akofe, "Optimization of 
a Refinery Crude Distillation Unit in the Context of Total Energy Requirement," NNPC R\&D Division, Port Harcourt, 2003.

[10] P. Domijan and D. Kalpić, "Off-Line Energy Optimization Model for Crude Distillation Unit," Ph.D. Thesis, University of Zagreb, Croatia, 2005.

[11] A. Fazlali, S. Hosseini, B. Yasini and A. Moghadassi, "Optimization of Operating Conditions of Distillation Columns: An Energy Saving Option in Refinery Industry," Songklanakarin Journal of Science and Technology, Vol. 31, No. 6, 2009, pp. 661-664.

[12] N. kozarev, F. Keil and S. Stoyanov, "Computer Aided
Steady State Control of Crude Oil Distillation," Journal of the University of Chemical Technology and Metallurgy, Vol. 45, No. 4, 2010, pp. 401-406.

[13] A. Benyoucef, "Oil Refining Planning under Price and Demand Uncertainties: Case of Algeria," 29th USAEE/ IAEE North America Conference, Calgary, 14-16 October 2010, pp. 1-19.

[14] M. K. Hassan, A. Kandeil and A. Elkhayat, "Improving Oil Refinery Productivity through Enhanced Crude Blending Using Linear Programming Modelling," Asian Journal of Scientific Research, Vol. 4, No. 2, 2011, pp. 95-113. doi:10.3923/ajsr.2011.95.113 